\title{
The Redefinition of ASD - A Collective Outlook
}

\author{
Sandra Patrícia Pereira, Tereza Ventura \\ KIE: Knowledge, Innovation and Education, Portugal
}

\begin{abstract}
This article is the second of a series of reflective reports on a work in progress that aims to measure the transformative impact of a child with Autism Spectrum Disorder within his/her intervention nucleus in a bidirectional logic of personal and social learning and development. The family is studied as a mobilizing agent of the community for the definition of a common project in which everyone will be subject and object of transformation and learning. The problem is deepened, moving from the family domain to the volunteer's social context. The program is described and how it prepares and monitors learning and practices. A qualitative methodology was adopted, using semi-structured interviews and focus groups, trying to understand how the love for a different child allowed preparing an action plan in which shared responsibility, belonging and unity gave birth to a new idea of a learning community - the Son-Rise family.
\end{abstract}

\section{Introduction}

This communication follows a preliminary article attempting to verify the transformative impact of a child with Autism Spectrum Disorder within his/her intervention nucleus (18 members, between 37 months and 42 years old), thinking about education as a multilateral process in a learning community. It aims to understand this nucleus (parents, child, fourteen volunteers) as an ecosystem based on the egalitarian dialogue concept, studying interactionist practices, based on the collective belief that a systemic evolution necessarily results from the capacity for individual transformation, in a dynamic of mutual influence.

The child in question will be named G, 34 months old, male and diagnosed with an autism spectrum disorder. In the initial diagnosis, he presented a great impairment in all areas evaluated, denoting a lack of consistency in visual contact, inexistence of verbal and non-verbal communication, and a null period of interactive attention. He showed lack of facial expression, as well as restrictive interests and exclusive and repetitive movements. His condition seemed aggravated by widespread hypotonia, which inhibited motor development; by an avoidant eating disorder, associated with the oral hypersensitivity that he manifested and the irritable bowel syndrome he suffered from. He is methodical and reveals discomfort facing unpredictability and excessive sensory stimuli.

After the diagnosis, the family worked out their beliefs, developed their resilience and took on the responsibility of defining an intervention program that would allow only their child to be the only one to set the limit of his development [1].

They adopted the Son-Rise Program (SRP) as their method of intervention, having as a structural pillar the resorting to elements of the community, in a volunteer way, as mediators and promoters of learning and development. They selected, recruited and taught volunteered to give life to a community governed by the common goal of optimizing the child's zone of proximal development. They nurtured the team spirit and used their skills and tools to work the group's cultural, emotional and social intelligence, contributing to the dual purpose of teaching and learning.

Collectively, they affirmed themselves as a space of exchanges and social interactions that can awake the potential development of all the participants. They believed in the power of sharing and cooperation, valuing democratic dialogue and inclusion, promoting feelings of shared responsibility, belonging and unity that gave birth to a new idea of learning community - the Son-Rise family.

They inspired other families who showed interest in the method and curiosity for the complicity and synergy created around that team. Several parents of children with ASD sought help in this learning community and the information and knowledge were widely shared. This contagion has been rampant and other Son-Rise Families have emerged, creating an informal alliance in which together they promote and motivate themselves.

It is important to point out that this development of collective potential has occurred without planning and in an unpretentious way, as a natural result of the sociointeractional exchanges promoted by the method itself, by the learning derived from reflection and by the respect and profound gratitude of this family towards those who, in an altruistic manner, still unaware of the transforming power of a different child, accepted to participate and change for the sake of love.

Reflecting on the power of resilience and the role of these new learning communities in society, promoting the democratization of lifelong learning and development are aspects to consider in the context of an inclusive, 
cooperative, shared and participated citizenship that longs for a society of everyone and for everyone.

\section{Autism Spectrum Disorder}

The American Psychiatric Association [2] presents autism as a complex neurodevelopment disorder that manifests itself with great variability in the intensity and in the form of symptomatology. Taking into account this variability, the denomination Autism Spectrum Disorders (ASD) was adopted, allowing a single categorization of the continuous diagnosis, adapted to each individual through the associated specifiers and deficits that best represent the heterogeneity of the behavioral phenotype of that individual.

This spectrum is portrayed as a behavioral and relational dysfunction that concomitantly presents persistent impairment in social communication and restricted, repetitive and stereotyped patterns of behavior, interests or activities [2, 3]. Based on the perceptions of the studied family in this article and the method of intervention adopted by them, it is assumed, however, that autism, although having behavioral manifestations, is, in fact, a socio-relational disorder [4].

Etiology is assumed to be multifactorial, involving genetic, neurological and environmental causes.

The first clinical manifestations usually occur before 36 months of age, completing the diagnosis between the ages of 3 and 4 years, when the child is perfectly inserted in a social context where the expression of the symptomatology is more evident.

According to the data from the Center for Disease Control [5], the prevalence of the disease is $1 / 68$, reaching $1.47 \%$ of the world's population, being four times more frequent in males.

Given the aforementioned difficulty in defining etiology, several intervention models/programs are used. In this article, the SRP method is essentially approached, since it was the one that was chosen by the studied family, which best corresponded to their beliefs and expectations of the intervention.

\section{Family}

Assuming ASD as a socio-relational dysfunction, the family takes on a particular role since it represents one of the main socialization contexts, being the first mediator between the child, the surrounding environment and culture. Thus, it becomes fundamental to clarify the concept of family, the factors of imbalance and stress that interfere with him (the protective aspects), as well as the needs in his development.

As a result, the family, in the systemic and ecological adopted perspective, is presented as an open interactional system, constituted by elements linked by a set of relationships, integrated in other subsystems, with which it develops, influencing and being influenced internally and externally in an ongoing process of development.

Thus, and after reviewing the reference literature, the diagnosis of ASD seems to present distinct, yet penetrating and bidirectional, influences throughout the family, being necessary adjustments in the economic, social, recreational, domestic, affective, educational aspects, as well as in the family identity. An effective and immediate multidisciplinary follow-up of the family is fundamental, capable of welcoming the diagnosis and a faster passage through the various phases of mourning, promoting reorganization, emotional adjustment and family health. Despite the quality of the follow-up, the process of acceptance is time-consuming since there is a need to mourn the idealized baby. The family needs to appeal to their emotional fertility, letting the real child be reborn in their imaginary, idealizing him and accepting him no matter the limitation or difference.

This capacity for reorganization and acceptance is significantly correlated with the resilience of each family, that is, with the capacity of self-regeneration, not allowing them to be destroyed by adversity, trying out strategies capable of overcoming challenges and promoting growth in critical moments. The literature points out that factors such as knowledge about the child's problem and the most effective strategies of action; a stable socio-economic level; the social support; a structured and supportive family environment, permeated by commitment and flexibility; high levels of communication and interaction; internal and external coping strategies; a positive outlook on life; and a family belief system are agents that promote the resilience of families of children with ASD.

A positive adaptation, permeated by optimism and acceptance, seems, as described in the literature, capable of promoting feelings of hope and control, fundamental to determine the quality of the parental relationship, the precocity of the intervention, as well as the family involvement in this process.

Currently, a paradigm change regarding the role of the family in children with ASD has been evidenced, starting to occupy a prominent place in the most varied models of intervention, particularly in the parents. It seems to be understood that parents are one of the best resources of the children, both for their knowledge and for the relationship with them. The training of the parents presents itself as one of the most efficient answers to a dysfunction that, due to its prevalence, begins to be assumed as a public health problem that requires not only an early diagnosis, but also a concerted strategy that breaks with the exclusivity of the medical model to establish the focus on a social model oriented towards the family and the environment. The empowerment of parents/caregivers and the use of natural contexts as intervention scenarios begin to be the basic features of 
this new paradigmatic model. With training and skills, parents can become multipliers of knowledge and carry out therapeutic processes with their children, being able to create a network of sharing capable of reaching a larger number of families in the community.

The literature positively and significantly correlates the intensive nature of the intervention with its success, pointing to an ideal weekly duration of forty hours, only achievable with the inclusion of the parents as therapeutic agents. These parental preparation and training have, as it is evidenced in the literature read, a direct and significant repercussion on the child, but also a renewing impact on the parents. They abandon the feeling of powerlessness to consider themselves as active and preponderant elements in the definition of a strategy of action for their children, perceiving themselves as agents of change that unblock opportunities and promote the potential of that child.

\section{Early Intervention and Neuroplasticity}

Given the specificity of the challenges presented in ASD, an early, immediate and intensive intervention is essential since, no matter the scientific perspective and/or intervention program or adopted method, it is understood as one of the predictive success factors, being determinant to stimulate the children's developmental levels, enhancing their abilities and stimulating the neuroplasticity necessary to minimize the symptoms and acquire the skills.

This consensus regarding the importance of early intervention in ASD is universal since science considers possible that intervening in early childhood, at a stage where the central nervous system is more plastic and permeable, attenuates symptoms as well as stimulate and develop new synaptic connections.

It is known that autism starts when the neurons that coordinate the socialization and communication skills present themselves at their best moment of development and permeability. As such, in observance of some risk factor, an intervention plan should be initiated immediately to optimize the greater cortical plasticity associated with this development phase, instead of directing it to the moment of a definitive diagnosis. Several studies prove an unparalleled rate of development in children under five compared to the rest ${ }^{[26]}$. Research legitimizes this finding by stating that although neuronal plasticity is a reality at any point in the individual's life, it will be easier to train a new competence than to annul or extinguish an already crystallized symptom and then to train the competence that will replace it.

By analyzing the literature, it is verified that the more recent it is, the more it is certified the possibility of early detection of risk factors and immediate response, allowing to increase the success rates of the intervention. Research suggests that the first four years of life is a critical period because the pace of development is most accelerated and there is a greater vulnerability and susceptibility to external stimuli, favoring the mitigation of the original functional limitations, training new skills and promoting new connections capable of enhancing the functional rigor of neural circuits.

Neuroplasticity is thus the ability of the brain to remap the connections of nerve cells resulting from mental stimuli that can be activated according to the sociocultural experience of the individual and that allow the creation of new ways for neural communication. Brain plasticity may occur by eliminating neurons that are not adequately stimulated (apoptosis), modifying the morphological and functional dynamism of the neurons through the strengthening of their neurotransmitters and modifying the structures involved in synapses and neurochemical changes.

As the benefits of early intervention and neuroplasticity are well described, reaffirmed and consensual in the literature, the same does not occur with the analysis of the cerebral connections observed in children with ASD. If some studies point out poor connectivity between neurons, translating into less efficient long-distance connections, others converge to neural hyperstimulation in specific brain areas associated with excess synapses. This fact seems to be justified by a slower process of apoptosis or neural pruning, culminating in an overloaded brain of unspecified and super-reinforced connections that harm its typical development, hampering learning, acquisition and refinement of new skills and competences.

The bet on the study of brain connections and the reaffirmation of brain plasticity are affirmed as sources of hope capable of operating profound changes in the definition of intervention plans focused on the adaptability of the brain influenced by the environmental stimulation. By thinking of our capabilities and abilities as competences, mostly shaped by the environment, the brain can be appropriated to the desired development, giving the right stimuli and experiences, operating a significant change in the life trajectory of the child and his family.

In short, modifications occur throughout life, through the development of learning ability and the refinement of acquired skills; however, the moment of greater plasticity coincides with early childhood, a critical period of brain development, in which flexibility and neural permeability are more expressive, being predictive of greater and faster success.

The intervention programs should therefore bet on the unlimited potential of each child, working the adaptability and plasticity of the brain; the precocity and frequency / daily intensity of training and the family as an optimal element of transformation.

After several years of research, it has been shown that early intervention accelerates the child's development; 
improves family functioning and reduces future costs with special education and rehabilitation services.

\section{The Son-Rise Program (SRP)}

The SRP is an intervention model that aggregates the biomedical and educational approaches in a symbiosis that is completed with the intervention of the families [7]. It understands autism as a difficulty in connection and social interaction, in which the behavioral impairments are perceived as attempts by the child to preserve his sensory, motor and cognitive balance in a world that he does not yet understand. It began in the 1970's when Barry and Samahria Kaufman did not resign themselves to the prognosis associated with their child's severe autism diagnosis and developed their own home-based approach to affectivity, acceptance, motivation and belief in Raun's potential. Through the joining technique, they attempted to create a connection that would allow them to rescue Raun from his solitary world, giving him control and the possibility to manage his timings in a sensory controlled and predictable space. Assuming a sociointeractionist perspective, where some saw defects, these parents found opportunities. They believed in the precedence of learning about the development and in the interaction as an enabler of acquisitions [8].

After three and a half years of intensive work, Raun, who had been assessed as having an IQ $<30$, recovered completely from autism, developing a neurotypical development. He completed the Biomedical Ethics course and is currently the CEO of the Autism Treatment Center of America, founded in 1983 by his parents [4]. The success of this intervention seems to confirm the importance of the quality of social interactions and the collaborative dynamics to strengthen the Zone of Proximal Development, as Vygotsky affirmed, contributing to understand that the individual's learning capacity is determined not only by biological factors, but also, essentially, by the ability of the support system to relate itself with the individual's cognitive structures.

The SRP is intended to enable parents to take charge of the intervention, transmitting them the confidence they place in the development of children and showing them that autism does not have to be a life sentence.

The first step is to train the parents, welcoming them, encouraging them to appreciate the difference of their child and to believe in their abilities. At the same time, parents are taught to use the educational, attitudinal principles, techniques, and tools that make them the most effective educators of their children. They are also confronted with the need to create a playroom that promotes a great learning environment, great for the sensory processing and where inputs are controlled and diminished. The concern with the physical space of the intervention meets Vygotsky who defended that people with disorders are capable of benefiting from the learning process, like the rest, provided that they are properly stimulated in a receptive educational environment and conducive to interactive exchanges [8].

The Son-Rise Program offers several treatment options, where the intensive home programs (40 to 56 hours per week) seem to present more expressive success rates [9].

Since this is a 1:1 intervention, in sessions lasting no more than two hours, there is a need to co-opt a large number of volunteers who are guided by the same principles and work for clear and common goals. These volunteers will be the child's eyes to the world, trying to rescue him from a state of inertia unable to leverage learning and promote development.

The empowerment of parents, the belief that it is in social exchanges that learning resides, the use of natural contexts as intervention scenarios and the need to create a cohesive work team have encouraged the creation of learning communities where all the intervenients can be simultaneously learners and multipliers of knowledge, creating a network of sharing in which the whole overlaps the part in the pursuit of a common goal.

\section{Learning Communities (LC)}

The concept of Learning Community, not being a recent concept, since it is based on theoretical assumptions related to Vygotsky's socio-interactionist and Brufenbrenner's ecological views, seems to gain importance at a time when it is assumed that the significance and effectiveness of learning are supported by the interaction and co-construction of knowledge [10].

Vygotsky, by introducing the concept of Zone of Proximal Development (ZPD) as a mediator between real development and potential development, where learning is leveraged through the sharing and the quality of collaboration with more experienced individuals, cements the focus on mediation and the humanization of learning. Thus, understanding the ZPD, as a constantly changing psychological domain in which, through support techniques (scaffolding), one consolidates emerging functions and promotes human development, allows a dynamic conception of intelligence as a construct of the individual's sociocultural interactions [11].

The idea of democratization of learning emerges, assuming that all are capable of learning and evolving in society, regardless of their current condition, since only a tiny part of human potentialities are optimized, while the rest is waiting for an adequate profitability of the ZPD. Thus, it is believed that, using appropriate support techniques and permeated by the quality of mediation and socio-cultural interaction, it will be possible to intervene in the developmental path of a society and, consequently, of the individuals that integrate it. 
Learning is thus assumed as the result of a process of exchange, in which individual and environment mutually influence each other, being in constant movement and transformation.

In sum, Vygotsky's perspective is based on the belief that the highest mental functions emerge from social processes and that these processes are formed through cultural tools or artifacts that mediate the interaction between individuals and among them and their physical involvements, echoing effects both in the user and in the surrounding context [11].

Accepting this ideology and fortified by a common interest, the first learning communities emerge as spaces of transformative interaction, based on the defense that difference and equality are compatible values, mutually enriching and able to promote equity and learning for all intervenients.

These communities take back the defense that the human condition is built along a historical-cultural process guided by social interactions in which development depends on the learning opportunities and interpersonal relationships established, considering that all the cognitive functions of the individual begin in an interpersonal process that, as a result of a long series of developmental events, will become an intrapersonal process [12].

With the creation of learning communities, the paradigm of education is changed, believing that learning must take place in a collaborative, cooperative and instrumental dynamic of sharing knowledge, skills and objectives, capable of transforming the course of personal and collective development. A dialogic and reflective learning performance is experienced in which everyone is subject and object of transformation and learning.

Learning communities, therefore, constitute themselves as an intellectual, social and cultural environment that facilitates a bidirectional learning promoting interaction, collaboration and collective participation, developing a sense of positive interdependence in which everyone, through practice, evaluation and reflection, empowers their capacities and blurs their limitations.

\section{The Son-Rise Program and the creation of a Learning Community}

The SRP shares Vygotsky's theory by defending the learning capacity of all individuals, relegating to society the duty to find the most fruitful strategies to trigger and mediate this process. In his approach, it is proposed the definition of a family intervention program depending on the selection, training and monitoring of a team of volunteers capable of collaboratively using scaffolding strategies, capable of promoting learning and development [13], encouraging the initiative, within a logic of transient support and progressive autonomy.

Given the scientific evidences that show a positive and significant correlation between the weekly duration of the intervention and its success $[7,13,15]$, the studied family decided to implement the Full Time - Level II Program, with a weekly duration of 40 to 56 hours. In order to enable this intensive implementation of the program, it was necessary to select, co-opt and train fourteen volunteers who, at the end, are part of a new learning community with the common goal of mediating G's learning and development and, simultaneously, promoting the enrichment and transformation of all intervenients.

The constitution of this team was a very rigorous process, where the parents assumed that the assertiveness in the selection of the volunteers would be predictive of the quality of the exchanges and social experiences promoted and of the proficiency in motivating $G$ to integrate a social and cultural context that promotes significant and internalizable learning [13]. Thus, they attempted to select individuals from various social sphere quadrants, with distinct personalities, but who shared unconditional love for $\mathrm{G}$ and the entrenched belief in his unlimited potential. Commitment, creativity, energy, empathy, sensitivity, critical and reflective spirit were some of the characteristics that parents sought in volunteers. Age, academic qualifications or social and economic status were not considered as selection criteria. The diversity of opinions and experiences was valued, believing in the power of egalitarian dialogue and dialogic interactions, highlighting the individual contribution to the development of society, as well as the role of the collective in the construction of the individuality of each one.

The recruitment and initial training of the volunteers took place in 3 sessions of 120 minutes each.

In the first session, G's narrative of the development was made, explaining his problems, his impairments and motivations. After, the fundamentals and principles of the SRP, as well as its intervention strategy were presented, immediately assessing the interest of those present to join the team of volunteers. It was observed that all those present immediately identified themselves with the basic philosophy and guidelines of the SRP, feeling privileged that they were selected to develop such a dignified project, believing that, more than mediating the development of a child, they would improve their own development, as a consequence of interactive exchanges with all of those involved, and also as a result of the selfreflexive and critical practices imposed both in the personal and social dimensions [16].

In the second session, the SRP developmental model was presented and the techniques to be used within the playroom analyzed in detail, complementing with videos as examples. The SRP considers ASD as a social, relational, interpersonal, and interactional disorder, and 
as such, its social curriculum is highly focused on four critical areas of intervention: eye contact and non-verbal communication, verbal communication, period of interactive attention and flexibility. These fields of intervention must be at the heart of the volunteers' action as well as the target of all invested tools.

The "joining" technique, being the pillar of the SRP, is priceless in allowing, through authentic acceptance, to establish, whenever the child is unable to build, connections, bonds and relationships that will be the basis of all learning.

In the third session, pair and group work were done to stimulate creativity, unlock some attitudinal constraints and promote team bonding. The self-efficacy perception, described by Bandura, was simultaneously one of the aspects worked, since the parents gave importance to their strong predictive value in the persistence and pursuit of the common objective [17].

In this new learning community, there are 14 volunteers (eight females and six males), a physiotherapist and the nuclear family (mother, father and child with ASD), in a total of 18 members, with the ages between 33 months and 60 years.

Given the insistence and interest of two children belonging to the family in their involvement in G's problem and their commitment to help him overcome his difficulties, the group chose to integrate them in the volunteer team, because the relationship with these children will be, in their perception, the beginning of the child's familiarization with his peers and an added value for the development of specific competences of the social curriculum. Social interaction among peers is also one of Vygotsky and Brunner's constructs, by stating that learning happens through collaborative knowledgebuilding projects in which the roles of all intervenients intertwine and complement each other, being everyone, regardless of the roles exercised, apprentices in an interactive and progressive process of knowledge construction [18].

The physiotherapist, not being a volunteer, belongs to the team, and she was the one to express, at a later stage, her interest in collaborating in this common project. The results obtained, as well as the precepts inherent in this and in any learning community were the factors that were the basis of her decision, sharing the capital objectives of this group.

This team includes four couples, two of them with a minor child, being the remaining members single and with no descendants.

With the exception of the children, all volunteers completed the 12th grade, having six members completed a university course. Only one of the elements has training in the area of autism and special educational needs, and none of the elements of the team has worked with this problem before. The work areas are distinct and comprehensive, focusing on education, health, engineering, management and service to the public.

Ten of the volunteers belong to the extended family, the remaining ones are the child's former educator, a friend of the couple with training in the area and the mother of a teenager on the autism spectrum.

With the exception of the children, who have 30minute playroom sessions, the remaining participants have 120-minute sessions, twice a week. This is considered the minimum amount of time for the child to establish a bond with the volunteers, and so being able to consider them as non-invasive and reliable elements, capable of arousing his interest to the world and people. These sessions are observed through a mirror glass, and, at the end, the feedback of the follow-up is presented, referring to the techniques used, as well as some suggestions for acting and overcoming, giving value to the qualities, availability and love evidenced and promoting the feeling of belonging. All team members consider that this follow-up process is essential for pursuing the ultimate goal since it promotes selfreflection, stimulates creativity, encourages action in the limit of its potential, challenging the individual and collective ZPD in a dynamic to grow, allowing the growth [13].

The continuous assessment is an essential process for the readjustment of the communitarian journey.

The team meets monthly for monitoring and training, with the purpose of sharing ideas and experiences, analyzing the set objectives and their level of development and redefining objectives, strategies and activities. It is also the parents' goal with these meetings to inspire the team by promoting sharing and building bonds among the members of this new family, guiding them in maintaining a powerful focus: the belief in the unlimited potential of their child.

In the opinion of the team members, this process of shared and participated monitoring and assessment of the practices proposed and mediated by the SRP is unanimously considered as one of the added value of this educational space that they integrate.

\section{The SRP - E(A)ffective Educational - Learning Communities}

The principles and foundations of the SRP are echoed in the basic philosophy of the learning communities in all of the above mentioned aspects, and particularly in the belief that any meaningful and perennial learning is effective only when the conative, emotional, and affective functions are integrated and synchronize. Thus, emotional intelligence, motivation and social cognition are essential premises in the definition of this learning community, extolling the priceless value of the interpersonal dynamics established between the learning 
brain and the more experienced brains, in a search for socially and emotionally competent individuals [19].

It is believed, therefore, that effective learning and consequent transformation requires a large emotional investment capable of acting in the brain, which, though compartmentalized, operates in an organized, shared and continuous way. This belief in neuroscience is supported by studies that prove that, since the human being needs to be taught in order to learn, this path must be structured in a social and emotional context, in a dimension of sharing in which both learn driven by the emotion that presents a formative role in cognitive processes, in an inseparable neurofunctionally dynamic of evolution.

Considering that learning results from social and emotional interaction between an experienced being and an inexperienced being in which the emotions of some merge with the cognitions of others, a family, in their executive function of managing the home program, explicitly works the attitude of their volunteers, seeking their emotions as vehicles of effective and affective learning, in the belief that the success of the program depends on the emotional competence of each intervenient [19].

Feelings of security, comfort, unity, appreciation, belonging, self-concept and self-efficacy are stimulated in the feedback sessions and biweekly meetings, letting them act on a cognition, allowing each volunteer to adapt to the constant inner changes and then learn to learn in a process in which he also teaches.

From the analysis of the results obtained, it is possible to verify changes that are evident in all the participants. Is this change the meaning of learning? Will the intervenients be able to self-analyze and adopt a reflexive attitude that allows them to incorporate the changes in the long term, potentiating the transformation? Will all be transformed or will some be lost in the traces of transformation? Will triangulation emotions, learning and brain influence this learning and transformation? Will there be marks in the surrounding society? These are some of the questions that are posed in a later phase of the research in which we will try to establish convergences between the Sciences of the Education and the Neurosciences, in an effective articulation between both, aiming at their complementarity.

\section{Methodology}

This article integrates a systemic case study with a strong descriptive tendency intended to analyze the family system of a child with ASD in its multiple dimensions, beliefs and perceptions. A qualitative methodology was mostly adopted, based on the narrative of the facts. With this methodological option, it was possible to highlight the importance of the individuals involved, as well as their beliefs and perceptions, seeking to understand the problem of ASD and its comprehensiveness in the lives of those who experience and perceive it.

Taking into account the proposed objectives, semistructured interviews and the focus group technique were defined as instruments of data collection, both of which were directed to all the individuals involved in the study, except for the child with ASD.

It was valued the researcher interaction with the field and the importance of his/her subjective interpretation as an explicit part of the production of knowledge.

\section{Discussion of intermediate results}

The present study used, as sources of information, the minutes and written reports produced in the monitoring process, complemented with a set of interviews to all the intervenients in this Son-Rise Community. Both sources provided a collection of information that was the subject of content analysis.

After fifteen months of intervention, it was found that feelings of inclusion, acceptance, recognition and equality in the design of the action strategy promote feelings of personal and social fulfillment, capable of influencing all the quadrants of their lives. They point out that, more than a method of intervention, this program and this way of exchanging learning imposed themselves as a new way of being and thinking about life and citizenship. It is important to add the generalized belief that everyone benefits by integrating this voluntary scheme. They state that, along with all the theoretical and practical knowledge acquired during the training, a new identity accompanied by renewed beliefs and a more empathic and sympathetic inner potential has shown them that the impossible is only a little more time consuming, blossoming a new way of problematizing life. When there were asked about the time spent, they were unanimous in recognizing it as an investment in their personal, social and cultural education, expressing deep gratitude for sharing. It should be noted that, at the time of recruitment, the potential volunteers were confronted with the need to ensure their participation for a minimum period of six months in order to promote greater connection with the child and the rest of the team. They understood the pertinence of this imposition and, at the end of the first year of the intervention, they all expressed the desire to remain in the team until the final objective was reached. It should be noted that, for health reasons, two members suspended their participation, but continue to follow the progress of the intervention in order to remain capable of re-integrating the team. Another participant interrupted her activity due to maternity/breastfeeding, having returned three months later. To fill these absences, even if temporary, the parents formed four new volunteers who came to reinforce and "empower" this community.

After interviewing all the participants, it was possible 
to verify that acceptance and unconditional love are the dominant tone of the speech. The common goal is to see $\mathrm{G}$ go as far as he can and to see him independent is the limit. All have revealed that if G's development does not keep up with their high expectations, it will not be understood as a discouraging factor since any gain is a victory and changes are always possible as long as one continues to believe them. All reported that their strength rests on G's small achievements, increased intentional eye contact and interactive attention and deep commitment to the program.

According to reports, the common motivation in this project is love, belief in G's potential, the will to make a difference in the life of this family, as well as the possibility of being part of a "miracle". It was also a consensual reference the fact that everyone felt gratified to be part of a learning community that appreciates the inestimable value of the difference and equity, believing in the power of the interaction and cooperation in a project in which the objectives of the participants are closely linked to each other, not being achieved in any other way than the collective way. Feelings like the perception of self-efficacy, pride and overcoming are also shared by this educational community.

In short, this learning community presents itself as a project of social and cultural transformation that relies on the unlimited potential of individuals, preferring to focus on their potentialities, looking at the limitations as eventual focuses of opportunity. It also seeks to break with a society that, in Vygotsky's words, has remained a development-blocking agent for people with disabilities by infantilizing and underestimating their capabilities [6, $8,10,11,13]$.

Vygotsky, along with the SRP, facilitates the birth of these communities by advocating the absence of learning without interaction and mediation, by assuming sharing and collaboration as determinant factors of success. Social precedence over the individual is assumed, believing that the efficacy of the learning process is intimately dependent on the quality of the interactions with the other and with the environment. His perspective on the capacity of overcoming of the individual, allowing $\mathrm{him} / \mathrm{her}$ to act to the limit of his/her potential when using appropriate scaffolding techniques, introduced the concept of neuroplasticity that presents itself as one of the basics of the creation of this learning community that believes that intervening conveniently in the area of proximal development of this child may create new synapses, unblocking learning and promoting its integral development, reaching, that way the objective that was the basis of its association.

Thus, this learning community invests in prospective and creative interactions, permeated by the motivation and appreciation of the difference and diversity in a context in which the most experienced facilitators are able to operate transformations in the child, being reciprocally influenced by the interaction with all the intervenients and with the environment.

\section{Conclusion}

In a globalized and constantly changing society, it is fundamental to prod the capacity to reflect, to ponder and to problematize the future. To see learning as a collective process, resulting from meaningful and rewarding sociointeractional experiences, where the plurality of competences is valued and desired and where everyone feels valid and recognized, can contribute to a more inclusive society, being more respectful of the difference as a factor of enrichment.

Taking the limitations as opportunities, working out beliefs and shaping attitudes allowed this family to take control of the intervention designed for their child, benefiting, together with the whole volunteer team, from a unique learning experience, capable of revealing the potential of all intervenients, in a maxim of which unity is power and that learning is a lifelong process.

To verify the transformative impact of the intervention traced to a child at the heart of the community that promotes it is one of the great advances of this homebased program that, along with helping to learn, encourages rebirth; therefore, ASD could never be just a struggle of the family but an inevitable community commitment.

\section{Bibliography}

[1] Pereira, S. e Ventura, T., ASD - Not a Sentence for life but a Way of Living, Proceedings of the Canada International Conference on Education, June 26-29, 2017, Toronto, Ireland, pp. 297-303.

[2] American Psychiatric Association, Diagnostic and Statistical Manual of Mental Disorders, $15^{\text {th }}$ ed, Arlington, VA: Am Psychiatr Publishing, 2013.

[3] F. Maia, M. Almeida, L. Oliveira, S. Oliveira, V. Saeger; V. Oliveira and M. Silveira "The Importance of Embracing Parents of a Child Diagnosed with Autism Spectrum Disorder", Caderno de Saúde Coletânea, 2016, pp. 228-234.

[4] R. Kaufman, Vencer o Autismo com o The Son-Rise Program, PAPA-LETRAS, 2016.

[5] Center for Disease Control and Prevention. Prevalence of Autism Spectrum Disorder among Children Aged 8 Years: Autism and Developmental Disabilities Monitoring Network, 2010, 2014, pp.1-21.

[6] Pereira, S. e Ventura, T., ASD - A Change in Perception and Attitude, International Journal of Technology and Inclusive Education (IJTIE), Volume 7, Issue 1, ISSN: ISSN 2047-0533. 
[7] J. Coutinho and R. Bosso, "Autismo e Genética: Uma Revisão de Literatura”, Revista Científica do ITPAC, 2015.

[8] D. Costa, "Superando Limites: a Contribuição de Vygotsky para a Educação Especial”, Revista Psicopedagógica, 2006, pp. 232-40.

[9] K. Houghton, J. Schuchard, C. Lewis, C. Thompson, "Promoting child-initiated social-communication in children with autism: Son-Rise Program intervention effects", Journal of Communication Disorders, v. 46, Issues 5-6, 2013, pp. 495506.

[10] H. Catela, "Comunidades de Aprendizagem: em Torno de um Conceito", Revista de Educação, v. 18, n. ${ }^{\circ} 2,2011$, pp. 3145.

[11] C. Seth, "A Zona de Desenvolvimento Próximo na Análise de Vygotsky sobre Aprendizagem e Ensino", Revista Psicologia em Estudo, v.16, n. ${ }^{\circ} 4,2011$, pp. 659-675.

[12] F. Costa, "Comunidades Virtuais de Aprendizagem: Traços, Perspetivas de Estudo e Desafios às Instituições Educativas, Perspetivas, v. 1, 2012, pp. 59-75.

[13] L. Vygotsky, Mind in society: The development of higher psychological processes. Cambridge, MA: Harvard University Press, 1978.

[14] L. Segeren \& F. Fernandes, "Correlation between Verbal Communication of Children with Autism Spectrum Disorders and the Level Stress of Their Parents", Audiology Communication, 2016.

[15] H. Reis; A. Pereira; L. Almeida, "Características e especificidades da Comunicação Social na Perturbação do Espectro do Autismo", Rev. Bras. Ed. Esp., 2016, p. 325-336.

[16] M. Summer, G. Summer, "Creating Family Learning Communities", Young Children, 2014.

[17] A. Portella e R. Azzi, Crenças de autoeficácia e resiliência: apontamentos da literatura sociocognitiva, Estudos de Psicologia 29 (1), 2012, pp. 105-114.

[18] J. Bruner, Para uma Teoria da Educação, Relógio d'Água Editores, 1966-2000.

[19] V. Fonseca, Importância das Emoções na Aprendizagem uma Abordagem Neuropsicopedagógica, Rv. Psicopedagogia, 2016, pp. 365-84. 